estroika and glasnost in the socialist countries. In India the health sector too has got caught in this wave and beginnings have been made with the introduction of usercharges in public health institutions. The small mercies that the under privileged had in the form of free public health services too seem to be getting out of their reach. This must be prevented and countered, and the demand for a national health service must become vociferous before the corpo- rate and HMO type of 'health revolution' takes over in India and uproots the small legacy of public health services we already have. We have to demand that health becomes a right which the state must provide for unconditionally from the revenue it collects from citizens. The Bhore Committee report, though nearly half a century old, gives us the basic foundation from which we can build the apparatus of a national health service.

\title{
OVERALL PROGRAM STATUS
}

Immunization programs in developing countries have made remarkable progress since the inception of the Expanded Program on Immunization (EPI) in 1974 when it was estimated that less than 5\% of the world's infants were adequately immunized. Today, some $70 \%$ are being reached with a protective course of immunization by the first year of life. The development of the capacity to achieve these levels of coverage of infants represents a major public health triumph for the end of the decade of the 1980s.

High immunization coverage levels need to be achieved and sustaincd. Intensified immunization activities, including the use of national or local immunization days, should be directed at areas of low immunization coverage or where there is continuing transmission of disease. Each country should have an Immunization Plan of Action with integrates the targets of achieving at lcast $90 \%$ immunization coverage with all EPI antigens, poliomyelitis eradication, neonatal tetanus elimation and measles reduction, and, in areas. of risk, delivery of appropriate micronutrient supplementation. 